\title{
Effect of Nucleant Particle Agglomeration on Grain Size
}

\author{
FENG GAO and ZHONGYUN FAN
}

Solute accumulation/depletion in the liquid around a growing solid particle during the solidification of metallic melts creates a constitutionally supercooled (CS) zone that has a significant effect on the final solidified grain structure. In this paper, we introduce two mechanisms related to the CS zone that affect grain size: one is the grain initiation free zone (GIFZ) that describes the inability of nucleant particles located in the CS zone for grain initiation and the other is re-melting (RM) of solid particles due to overlap of CS zones. Based on these two mechanisms, we have systematically analysed the effect of nucleant particle agglomeration on grain size. We found that nucleant particle agglomeration has a significant effect on grain size and is responsible for the discrepancy between theoretically predicted grain size and the experimental data. In addition, our numerical analysis suggests that under normal solidification conditions relevant to industrial practice solid particle re-melting has little effect on grain size and thus may be ignored during theoretical analysis. A practical implication from this work is that significant grain refinement can be achieved by dispersing the nucleant particles in the melt prior to solidification.

https://doi.org/10.1007/s11661-021-06549-2

(C) Crown 2021

\section{INTRODUCTION}

GRAIN refinement leads to the improved mechanical performance of as-solidified materials due to both refined microstructure and reduced casting defects. ${ }^{[1]}$ It has been generally recognised that two crucial factors affect grain refinement: the presence of solutes in the melt and the existence of nucleant particles. ${ }^{[1-6]}$ During diffusion-controlled solidification, solute elements accumulate/deplete in the liquid adjacent to the solid-liquid interface, resulting in a constitutional supercooling (CS) zone. $^{[7]}$ The CS zone was found later to have a significant influence on both growth velocity of the solid and the grain size of the finally solidified materials.

Modelling of grain refinement has been a popular topic in solidification research. The first modelling work dedicated to grain refinement during isothermal solidification was conducted by Maxwell and Hellawell. ${ }^{[8]}$ They developed a numerical model to predict grain number density (related to grain size) according to the classical heterogeneous nucleation theory. In their work, a parameter, $1 / X$, was introduced to describe the growth restriction effect of solute,

FENG GAO and ZHONGYUN FAN are with the BCAST, Brunel University London, Uxbridge, Middlesex, UB8 3PH, UK. Contact email: zhongyun.fan@brunel.ac.uk

Manuscript submitted May 27, 2021, accepted November 14, 2021.

Article published online January 1, 2022

$$
\frac{1}{X}=m C_{0}(k-1)
$$

where $m$ is the slope of liquidus in the binary phase diagram, $C_{0}$ is the composition and $k$ is the partition coefficient. Maxwell and Hellawell's model explained for the first time why not all the nucleant particles can initiate grains: recalescence stifles grain initiation on those particles that have not participated in grain initiation. However, since the nucleant particles were assumed to have a mono-size, Maxwell and Hellawell's model was not able to tell which particle(s) can initiate grains.

Based on Maxwell and Hellawell's model, Greer et al. ${ }^{[9]}$ developed the free growth model by assuming that the nucleant particles have a log-normal size distribution. The free growth model clearly demonstrated that grain initiation occurs first on the largest nucleant particle(s) and then on progressively smaller ones. The free growth criterion shows that the grain initiation undercooling $\left(\Delta T_{\mathrm{gi}}\right)$ is closely related to the nucleant particle size $(d)$ :

$$
\Delta T_{\mathrm{gi}}=\frac{4 \gamma}{\Delta S_{\mathrm{v}} d},
$$

where $\gamma$ is the liquid/solid interfacial energy, and $\Delta S_{\mathrm{v}}$ is the entropy of fusion per unit volume. Based on the free growth criterion (Eq. [2]), a numerical model was developed by Greer et al. ${ }^{[9]}$ to predict grain size under different solidification conditions. They defined $1 / X$ in 
Eq. [1] as the growth restriction factor and denoted it as $Q$, and demonstrated that grain size is closely related to $Q$.

The concept of CS was qualitatively described in References 7, 10. Subsequently, Winegard and Chalmers ${ }^{[11]}$ proposed the CS-driven nucleation hypothesis and correlated CS with equiaxed grain formation during solidification. Based on this hypothesis, Qian et al. ${ }^{[12]}$ developed an analytical model for CS-driven grain formation to link the nucleation of new grains to the growth of a larger neighbouring grain. They pointed out that the average grain size is determined by two components: (1) the minimum amount of growth that is needed to establish sufficient CS for nucleating new grains; and (2) the spatial mean distance from the advancing grain front to the most potent nucleant particles available. Further work along this direction has led to the development of the interdependence theory by St John et al. ${ }^{[13]}$

In addition to growth restriction, the CS zone is also found to reduce the number of new grains. For solidification without recalescence, Quested and Greer $^{[14]}$ proposed a soft impingement mechanism related to the CS zone: grain initiation ceases after impingement of the CS zones of previously initiated grains. They used this impingement mechanism to predict grain size after directional solidification with a specified temperature gradient. Similarly, in the interdependence theory, ${ }^{[13]}$ a nucleation free zone (NFZ) related to CS was proposed to describe the failure of grain initiation by particles within the CS zones around previously initiated grains. At the same time, the solute suspended nucleation (SSN) zone that is the same as the NFZ was suggested by Shu et al. ${ }^{[15]}$ They developed a numerical model coupled with the free growth model to predict grain size of $\mathrm{Al}$ alloys and found that grain refinement of alloys with high solute content is controlled primarily by the SSN effect. ${ }^{[15]}$ However, Du and $\mathrm{Li}^{[16]}$ pointed out that the SSN effect can be neglected during isothermal solidification. The NFZ was later analysed numerically by Prasad et al., ${ }^{[17]}$ investigated experimentally using in situ observation ${ }^{[18-21]}$ and reviewed systematically by StJohn et al. ${ }^{[22]}$ although a thorough understanding of NFZ is still required.

In the free growth model, Greer et al. ${ }^{[9]}$ assumed that nucleation of $\alpha-\mathrm{Al}$ on $\mathrm{TiB}_{2}$ has already occurred prior to grain initiation due to its small nucleation undercooling. However, the nucleation and grain initiation were treated as the same process in most of the prior studies. More recently, Fan et al. ${ }^{[23]}$ suggested that early stages of solidification of a single-phase alloy may involve several individual stages, where nucleation and grain initiation are treated as two distinctly different processes. Heterogeneous nucleation is defined as a process that creates a 2D nucleus on a substrate that can template further growth of the solid phase. ${ }^{[24,25]}$ Further studies have shown that heterogeneous nucleation is independent of substrate size, but is closely related to lattice misfit, ${ }^{[25,26]}$ atomic level surface roughness ${ }^{[27-29]}$ and chemical interaction between the liquid and the substrate. ${ }^{[30]}$ In contrast, grain initiation describes a process that creates a $3 \mathrm{D}$ cap that can grow isothermally at a given undercooling. ${ }^{[23]}$ Grain initiation is governed by the grain initiation criterion ${ }^{[9]}$ and is strongly dependent on nucleant particle size. Based on this concept of early stages of solidification, two distinct grain initiation modes have been identified depending on the interplay between nucleation undercooling $\left(\Delta T_{\mathrm{n}}\right)$ and grain initiation undercooling of the largest nucleant particle $\left(\Delta T_{\mathrm{gi}}(1 \mathrm{st})\right)$ : progressive grain initiation (PGI) and explosive grain initiation (EGI). ${ }^{[23]}$ When nucleation is easy $\left[\Delta T_{\mathrm{n}}<\Delta T_{\mathrm{gi}}(1 \mathrm{st})\right]$, after nucleation (on all nucleant particles), grain initiation occurs first on the largest nucleant particle(s), followed by grain initiation on progressively smaller ones until recalescence. This is called progressive grain initiation (PGI). However, when nucleation becomes difficult $\left[\Delta T_{\mathrm{n}}>\Delta T_{\mathrm{gi}}(1 \mathrm{st})\right]$, a number of nucleant particles that have satisfied the grain initiation criterion at the nucleation temperature can initiate grains simultaneously and cause recalescence immediately after nucleation. This is called explosive grain initiation (EGI).

In addition to adequate solute concentration, a sufficiently large number of nucleant particles is a prerequisite for effective grain refinement. The final grain size is closely related to the total number of grain initiation events. However, the total grain initiation events may be altered by particle dissolution (e.g. $\mathrm{Zr}$ particles in $\mathrm{Mg}$ alloys $\mathrm{s}^{[4]}$, particle settlement and agglomeration (e.g. $\mathrm{TiB}_{2}$ particles in $\mathrm{Al}$ alloys ${ }^{[2]}$ ), particularly for these particles in sub-micro or nanometre size range. As a widespread phenomenon, particle agglomeration is commonly observed in processes where nano- or micro-meter sized particles are involved, such as processes for the production of metal matrix composites (MMCs). ${ }^{[31-35]}$ Taking $\mathrm{Al} / \mathrm{TiB}_{2}$ MMC for example, Ti- and B-containing salts are added to Al melt, resulting in a series of chemical reactions which produce sub-micron sized $\mathrm{TiB}_{2}$ particles in the melt. Watson et al. ${ }^{[35]}$ examined the $\mathrm{TiB}_{2}$ cluster size and size distribution in commercial purity $\mathrm{Al}$ (CP-Al) containing approximately $10 \mathrm{wt}$ pet $\mathrm{TiB}_{2}$. They found that the $\mathrm{TiB}_{2}$ clusters (agglomerates) have a log-normal size distribution. $\mathrm{TiB}_{2}$ particle agglomeration in commercial Al-5Ti-1B grain refiner was also confirmed experimentally by Han et al. ${ }^{[36]}$ Meanwhile, Han et al. ${ }^{[36,37]}$ found that ultrasonic treatment of molten Al-5Ti-1B grain refiner can only reduce the agglomeration of $\mathrm{TiB}_{2}$ particles to some extent. In addition, in situ observation of solidification of $\mathrm{Al}-\mathrm{Cu}$ alloys inoculated by $\mathrm{Al}-\mathrm{Ti}-\mathrm{B}$ grain refiner also confirmed the phenomenon of agglomeration of $\mathrm{TiB}_{2}$ particles in the melt. ${ }^{[38]}$ Although an explanation for the cause of clustering has yet to be agreed upon, it is proposed that reactant salts and/or oxide films may play an important role in the formation of $\mathrm{TiB}_{2}$ particle clusters. ${ }^{[39]}$ Most recently, Xu et al. ${ }^{[40]}$ investigated the effect of agglomeration of $\mathrm{Al}-\mathrm{Nb}-\mathrm{B}$ master alloy on grain refinement in $\mathrm{Al}-9 \mathrm{Si}-0.08 \mathrm{Ti}$ alloy. They found that the agglomeration of particles in the master alloy could be reduced by extrusion, thereby improving the grain refinement efficiency of the master alloy. Meanwhile, a modified free growth model was developed to predict the grain size, where the 
agglomerates were treated as having a log-normal distribution. ${ }^{[40]}$

In this paper, we present the results from a systematic investigation of the effect of the agglomeration of nucleant particles on grain refinement. After the introduction of the concepts of grain initiation free zone (GIFZ) and re-melting (RM) of initiated grains, a numerical model developed previously ${ }^{[23]}$ will be modified to analyse the effect of particle agglomeration, particle number density, solute concentration, and cooling rate on grain size. We will show that under solidification conditions relevant to the industrial practice nucleant particle agglomeration has a strong effect on grain size whilst solid particle re-melting has little effect and should be thus ignored during theoretical analysis.

\section{NUMERICAL MODELLING OF SOLIDIFICATION PROCESS}

$\mathrm{Al}-\mathrm{Cu}$ alloy inoculated by commercial $\mathrm{Al}-5 \mathrm{Ti}-1 \mathrm{~B}$ grain refiner is selected as a model system in this work for the following reasons: (1) $\mathrm{TiB}_{2}$ particles in the commercial $\mathrm{Al}-5 \mathrm{Ti}-1 \mathrm{~B}$ grain refiner have very small nucleation undercooling, being as small as $0.01 \mathrm{~K}^{[9]}$ This makes the grain initiation process fully progressive; (2) $\mathrm{TiB}_{2}$ particles are well characterised for morphology, surface orientation, particle size and size distribution, and number density. ${ }^{[1]}$ For clarity, the particles that act as nucleation sites are referred to as nucleant particles, free-growing solid particles (i.e., the initiated grains) as solid particles, and solid particles that survived after recalescence as grains.

Isothermal solidification of $\mathrm{Al}-\mathrm{Cu}$ alloys inoculated by $0.2 \mathrm{wt}$ pet of the commercial $\mathrm{Al}-5 \mathrm{Ti}-1 \mathrm{~B}$ grain refiner may involve the following stages ${ }^{[23]}$ : (1) prenucleation at temperatures above the nucleation temperature; (2) building on the precursor provided by prenucleation, heterogeneous nucleation at $T_{n}$ produces a $2 \mathrm{D}$ nucleus (a plane of the solid) on all the nucleant particles; (3) further decrease in temperature leads to grain initiation on progressively smaller nucleant particles; (4) grain initiation ceases at recalescence; and (5) free growth of the initiated solid particles and dissolution of the caps on nucleant particles that failed to initiate grains.

A numerical solidification model has been developed and the details were presented elsewhere. ${ }^{[23]}$ The values for the parameters used for numerical calculations in this work are tabulated in Table I. We assume that $\Delta T_{n}$ $=0.01 \mathrm{~K}$ for $\mathrm{TiB}_{2}$ particles in the commercial Al-5Ti-1B grain refiner. From the Eq. [2] and parameters in Table I, we can calculate the grain initiation undercooling for the largest particle $\left(\Delta T_{\text {gi }}(1 \mathrm{st}) \approx 0.02 \mathrm{~K}\right)$, which is larger than $\Delta T_{n}$. Therefore, the grain initiation, in this case, is fully progressive.

In a diffusion-controlled solidification process, solute elements are enriched/depleted in the liquid adjacent to the solid/liquid interface, forming a CS zone. Figure 1(a) illustrates schematically the concept of grain initiation free zone (GIFZ). The filled blue rectangles represent the nucleant particles, the light green sphere represents the solid particle (initiated grain), and the light blue sphere represents the $\mathrm{CS}$ zone. The liquid composition (the blue line) and the corresponding liquidus (the red line) in the CS zone are schematically shown in Figure 1(a). It is clear in Figure 1(a) that the undercooling inside the CS zone is smaller than that outside the CS zone. Therefore, nucleant particles located inside the CS zone will not be able to initiate grains. The GIFZ is hence defined as the space including the solid particle and its CS zone (Figure 1(a)). The width of CS zone in this work is assumed to be 4.6 times the radius of grain, which corresponds to 1 pct cut-off in the concentration profile. ${ }^{[13]}$ Therefore, the radius of the GIFZ $\left(R_{\mathrm{GIFZ}}\right)$ is 5.6 times the radius of the corresponding solid particle $\left(R_{\mathrm{s}}\right)$, i.e., $R_{\mathrm{GIFZ}}=5.6 R_{s}$.

Although both NFZ and GIFZ have the same physical origin, i.e., the CS zone, GIFZ is a better concept due to its clarity. Heterogeneous nucleation and grain initiation are two separate events that occur during solidification, and they should not be confused with each other. Heterogeneous nucleation creates a $2 \mathrm{D}$ nucleus to template further growth, ${ }^{[23,25,42]}$ whilst grain initiation marks the onset of growth without the need for further undercooling. ${ }^{[23]}$

Another phenomenon considered in this work is the re-melting of initiated solid particles due to overlap of the CS zones (Figure 1(b)). Impingement of the CS zones around growing solid particles results in overlap of CS zones, which in turn leads to a decrease in constitutional supercooling. This makes both growing solid particles thermodynamically unstable and leads to the eventual disappearance of the smaller ones. We refer to this phenomenon as re-melting of solid particles (Figure 1(b)).

In most of the modelling work so far in the literature, the nucleant particles are assumed to have a uniform distribution in the liquid (Figure 2(a)), i.e., no agglomeration. This means that all the nucleant particles have the same particle separation $\left(U_{0}\right)$, and $U_{0}$ is a sole function of particle number density $\left(N_{0}\right)$ :

$$
U_{0}=N_{0}^{-1 / 3} \text {. }
$$

Solid particle agglomeration in a metallic liquid is a norm rather than an exception. In powder form, an agglomeration is a pile of jumbled particles that are packed closely (i.e., particle touching is inevitable). However, the agglomeration in this work refers to clusters of nucleant particles densely populated in a liquid metal matrix. In this case, all particles in the cluster are wetted by the liquid. In other words, all nucleant particles are separated by the liquid phase, and hence there is no particle touching. This has been confirmed by microstructural observation, such as $\mathrm{TiB}_{2}$ particles in Al-5Ti-1B master alloys, ${ }^{[43]} \mathrm{Zr}$ particles in $\mathrm{Mg}-33 \mathrm{Zr}$ mater alloy ${ }^{[44]}$ and $\mathrm{MgO}$ particles in $\mathrm{Mg}$ alloys. ${ }^{[45]}$ In this work, we use $H$ (Figure 1(a)) to denote the nucleant particle separation (i.e., the nearest particle distance). For a given population of nucleant particles with a total number density of $N_{0}$, the particle separation is usually described mathematically by a Schulz 
distribution or log-normal distribution. Here for convenience, the distribution of $\mathrm{TiB}_{2}$ particle separation is assumed to be log-normal (Figure 2(b)):

$$
n_{H}=\frac{1}{\sigma_{H} H \sqrt{2 \pi}} \exp -\left(\frac{\left[\ln (H)-\ln \left(H_{0}\right)\right]^{2}}{2 \sigma_{H}^{2}}\right)
$$

where $n_{H}$ is the number of nucleant particles with a separation of $H, H_{0}$ and $\sigma_{H}$ are the geometric mean and standard deviation of nucleant particle separation, respectively. Thus, $H_{0}$ can be taken as a measure of degree of particle agglomeration; the smaller the $H_{0}$, the more severe the agglomeration of particles. Here we assume that $\sigma_{H}=0.876$, which is the standard deviation of the size distribution of $\mathrm{TiB}_{2}$ particles. ${ }^{[41]}$

Compared with the nucleant particles that have a greater tendency for agglomeration in the liquid, the growing solid particles are distributed much more randomly in the melt. Therefore, for analysing the effect of particle re-melting on grain size, the separation between growing solid particles, $S$ (Figure 1(b)), is assumed to have a Gaussian distribution (Figure 2(c)):

$$
n_{S}=\frac{1}{\sigma_{S} \sqrt{2 \pi}} \exp -\frac{1}{2}\left(\frac{S-S_{0}}{\sigma_{S}}\right)
$$

where $n_{S}$ is the number of solid particles with a separation of $S, S_{0}$ and $\sigma_{S}$ are the mean and standard deviation of solid particle separation, respectively.

In this work, the numerical model in Reference 23 was modified to analyse the solidification process with the following sequence: (1) calculation of the size of the largest $\mathrm{TiB}_{2}$ particle in a volume of $1 \mathrm{~cm}^{3}$ according to the particle size distribution; (2) with a given time step (normally $10^{-3}$ seconds for the cooling rate of $3.5 \mathrm{~K} / \mathrm{s}$ ), we calculate the temperature decrease from the specified cooling rate and the corresponding number of $\mathrm{TiB}_{2}$ particles that have satisfied the criterion for grain initiation. Based on the Eq. [4], these particles outside the GIFZ of previously initiated solid particles are then allowed for grain initiation, and those within the GIFZ will be denied for grain initiation; (3) repeat Steps (1) and (2) until recalescence occurs.

The average solid particle radius $\left(R_{S}\right)$ is calculated at the point of recalescence. Meanwhile, the number of solid particles whose separation distance is within the GIFZ is also calculated based on Eq. [5]. Then half of this number of solid particles (smaller ones) will assume to disappear during the subsequent solidification. The final grain size, $d$, is calculated from the final grain number density at recalescence, $N_{\mathrm{g}}{ }^{[9]}$

$$
d=\left(\frac{0.5}{N_{\mathrm{g}}}\right)^{1 / 3}
$$

\section{NUMERICAL ANALYSIS}

The afore-mentioned procedures were incorporated into a numerical model developed in Reference 23 to investigate the effect of nucleant particle distribution on the grain size of $\mathrm{Al}-\mathrm{Cu}$ alloys inoculated with $\mathrm{Al}-5 \mathrm{Ti}-1 \mathrm{~B}$ grain refiner $\left(\mathrm{TiB}_{2}\right.$ particle number density $N_{0}=10^{13} \mathrm{~m}^{-3}$ ) and solidified with a cooling rate of $\dot{T}$ $=3.5 \mathrm{~K} / \mathrm{s}$. Without considering GIFZ and solid particle re-melting, the predicted grain size data (filled triangles in Figure 3) are considerably smaller than the experimental results, ${ }^{[46,47]}$ being approximately 50 pct of the experimental grain size. The solid line in Figure 3 represents the calculated grain size with considering GIFZ and assuming a uniform distribution of $\mathrm{TiB}_{2}$ particles, which are similar assumptions made by Shu et al. ${ }^{[15]}$ and $\mathrm{Du}$ and $\mathrm{Li}^{[16]}$ The coincidence between the two sets of grain size data obtained with and without consideration of GIFZ suggests that GIFZ has no effect on grain size when the nucleant particles are assumed to have a uniform distribution in the melt. In other words, under such conditions, the probability for a nucleant particle to be located in the CS zone of a growing solid particle is very small. However, when the agglomeration of $\mathrm{TiB}_{2}$ particles is taken into consideration, the calculated grain size increases significantly (see Figure 3). For example, when the $H_{0}=10 \mu \mathrm{m}$, the calculated grain size (the dashed line in Figure 3) increases considerably from that with uniform particle distribution; when the agglomeration becomes more severe $\left(H_{0}=5 \mu \mathrm{m}\right)$, the calculated grain size (the dotted line in Figure 3) increases to a level that agrees well with the experimental results. ${ }^{[46,47]}$ Therefore, we can conclude that agglomeration of nucleant particles has a significant effect on grain size and is responsible for the discrepancy between theoretical predictions with uniform distribution of nucleant particles and experimental results (with particle agglomeration).

To understand further the effect of nucleant particle distribution on grain size, cooling curve and the number density of initiated solid particles $\left(N_{\mathrm{sp}}\right)$ for $\mathrm{Al}-1 \mathrm{Cu}$ alloy containing nucleant particles (either uniform or $H_{0}=5$ $\mu \mathrm{m})$ with and without consideration of GIFZ were calculated and the results are shown in Figure 4. From Figure 4, the following insights can be obtained: (1) the maximum undercooling, $\Delta T_{\max }$, is increased from $0.2 \mathrm{~K}$ without GIFZ to $0.43 \mathrm{~K}$ with GIFZ (Figure 4(a)); (2) without consideration of nucleant particle agglomeration, the GIFZ affects neither $\Delta T_{\max }$ (Figure 4(a)) nor $N_{\mathrm{sp}}$ (Figure 4(b)), and thus does not affect grain size (Figure 3); (3) compared with the case of uniform distribution, nucleant particle agglomeration $\left(H_{0}=5\right.$ $\mu \mathrm{m})$ increases the maximum undercooling by a factor of 2 (Figure 4(a)) and decreases the solid particle number density by a factor of 8 (Figure 4(b)); and (4) the overall effect of nucleant particle agglomeration is to increase the grain size by a factor of 2 (Figure 3 ), from $100 \mu \mathrm{m}$ without agglomeration to $192 \mu \mathrm{m}$ with agglomeration $\left(H_{0}=5\right.$ $\mu \mathrm{m})$. An interesting implication from Figures 3 and 4 is that the deagglomeration of nucleant particles can result in a significant increase in the efficiency of nucleant particles and a considerable decrease in grain size.

The size distribution of solid particles at recalescence with and without consideration of GIFZ was analysed for $\mathrm{Al}-1 \mathrm{Cu}$ alloy and the results are presented in 
Table I. The Main Parameters Used in the Numerical Calculation

Parameters (Symbol, Unit)

Value for $\mathrm{Al}-\mathrm{Cu}$

Partition Coefficient $(k)$

Liquidus Slope $\left(m, \mathrm{~K}(\mathrm{Wt} \mathrm{Pct})^{-1}\right)$

Heat Capacity $\left(c_{\mathrm{pv}}, \mathrm{Jm}^{-3} \mathrm{~K}^{-1}\right)$

Enthalpy of Fusion $\left(\Delta \mathrm{H}_{\mathrm{V}}, \mathrm{Jm}^{-3}\right)$

Diffusion Coefficient $\left(D, \mathrm{~m}^{2} \mathrm{~s}^{-1}\right)$

Gibbs-Thompson Coefficient $(\Gamma, \mathrm{Km})$

Log-Normal Distribution Mean of Nucleant Particles $\left(d_{0}, \mathrm{~m}\right)$

SD of Log-Normal Distribution of Nucleant particles $(\sigma)$

Nucleant Particle Number Density $\left(N_{0}, \mathrm{~m}^{-3}\right)$

Volume $\left(V_{0}, \mathrm{~m}^{3}\right)$

Cooling Rate $(\mathrm{K} / \mathrm{s})$

$0.13^{[52]}$

$-2.5^{[52]}$

$2.58 \times 10^{6[41]}$

$9.5 \times 10^{8[41]}$

$2.52 \times 10^{-9[41]}$

$1.42 \times 10^{-7[41]}$

$0.68 \times 10^{-6[41]}$

$0.876^{[41]}$

$1 \times 10^{13}$

$1 \times 10^{-6}$

3.5

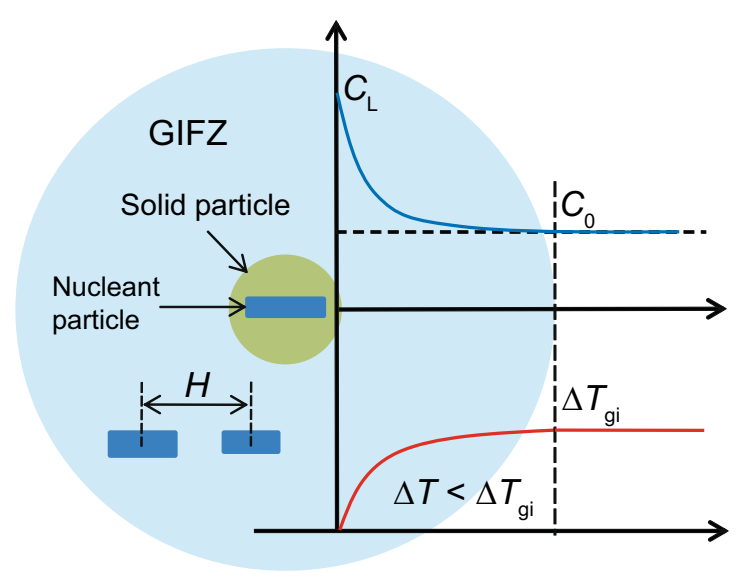

(a)

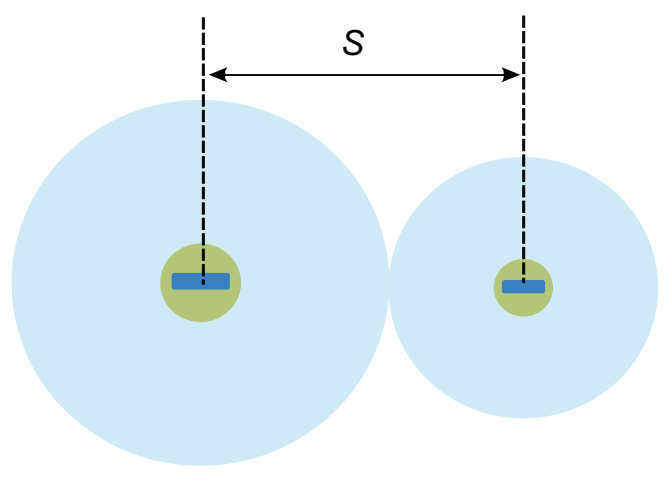

(b)

Fig. 1-Schematic illustration of the concepts of $(a)$ the grain initiation free zone (GIFZ) due to the constitutionally supercooled (CS) zone (the light blue sphere) around a growing solid particle (the lime sphere), and (b) re-melting of solid particles due to the overlap of CS zones. $H$ is the separation between two nearest nucleant particles, and $S$ is the separation between two nearest solid particles. The blue curve in (a) is the solute concentration profile around a growing solid particle and the red curve is the liquidus corresponding to the concentration profile (the blue curve) (Color figure online).

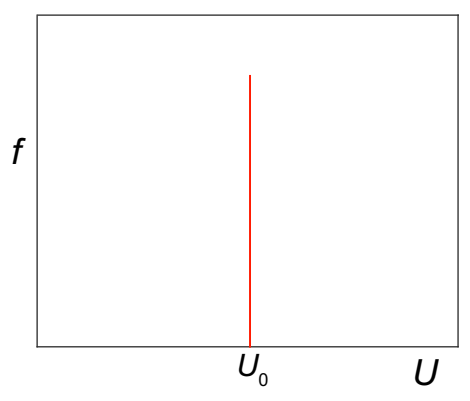

(a)

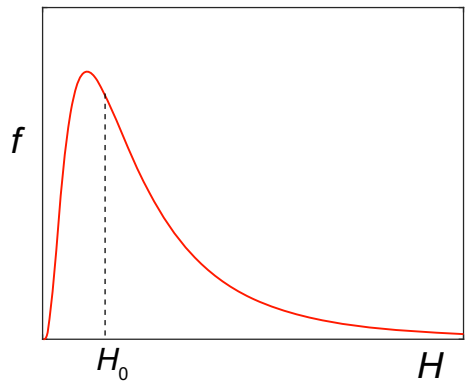

(b)

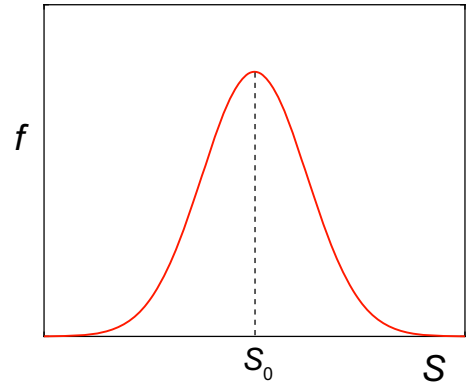

(c)

Fig. 2-Schematic illustrations of different types of distribution of particle separations: (a) uniform distribution with a mean separation of $U_{0}$, (b) log-normal distribution with a geometric mean $H_{0}$ and a standard deviation $\sigma_{\mathrm{H}}$, and (c) Gaussian distribution with a mean separation $S_{0}$ and a standard deviation $\sigma_{\mathrm{S}}$.

Figure 5. The size distribution of solid particles can be best described by a log-normal distribution for $\mathrm{Al}-1 \mathrm{Cu}$ alloy without consideration of either GIFZ or nucleant particle agglomeration (the dashed curve in Figure 5) but by a Gaussian distribution (random distribution) for
Al-1Cu alloy with consideration of both GIFZ and nucleant particle agglomeration (the solid curve in Figure 5). The mean solid particle size is $5 \mu \mathrm{m}$ without consideration of GIFZ and $14 \mu \mathrm{m}$ with consideration of both GIFZ and nucleant particle agglomeration. This 


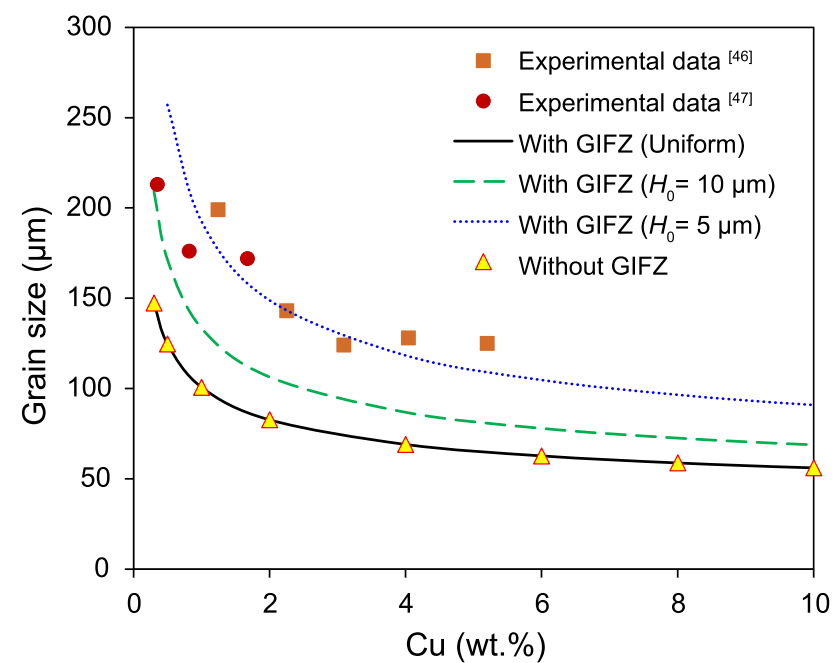

Fig. 3-Calculated grain size with and without consideration of GIFZ for Al-Cu alloys with $N_{0}=10^{13} \mathrm{~m}^{-3}$ and $\dot{T}=3.5 \mathrm{~K} / \mathrm{s}$ in comparison with the experimental data from the literature. ${ }^{[46,47]}$ The degree of nucleant particle agglomeration is represented by the geometric mean of nucleant particle separation $\left(H_{0}\right)$. The smaller the value of $H_{0}$, the more severe the particle agglomeration.

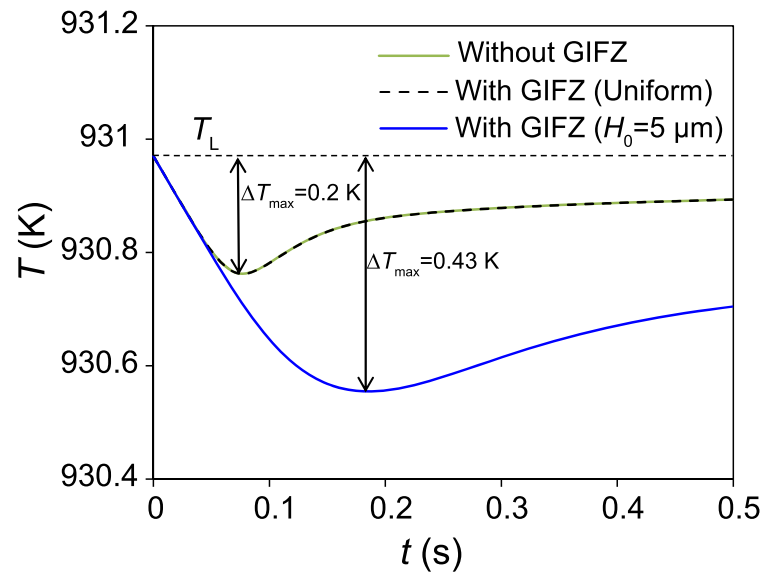

(a)

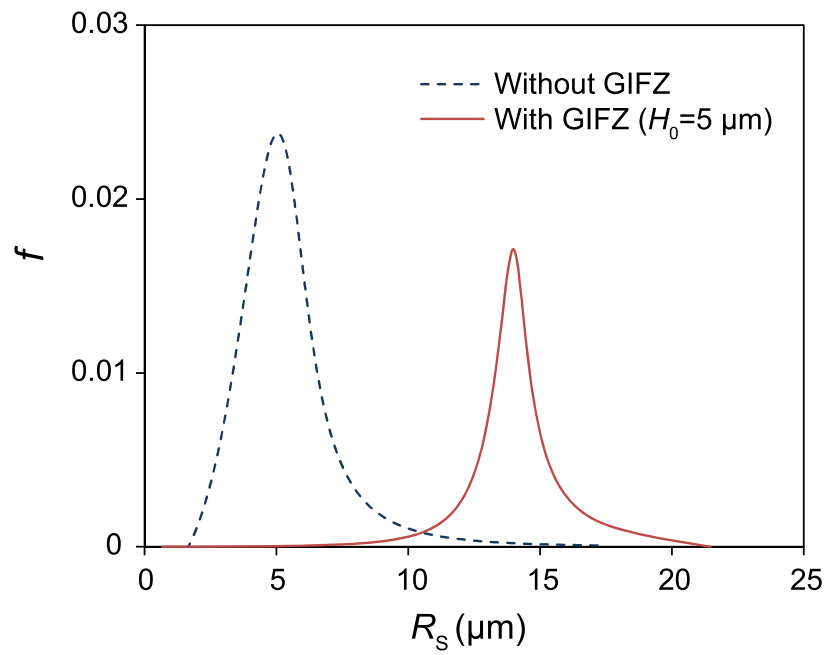

Fig. 5- Calculated size distribution of solid particles at recalescence $\left(R_{s}\right)$ with and without consideration of GIFZ for $\mathrm{Al}-1 \mathrm{Cu}$ alloy with $N_{0}=10^{13} \mathrm{~m}^{-3}$ and $\dot{T}=3.5 \mathrm{~K} / \mathrm{s}$.

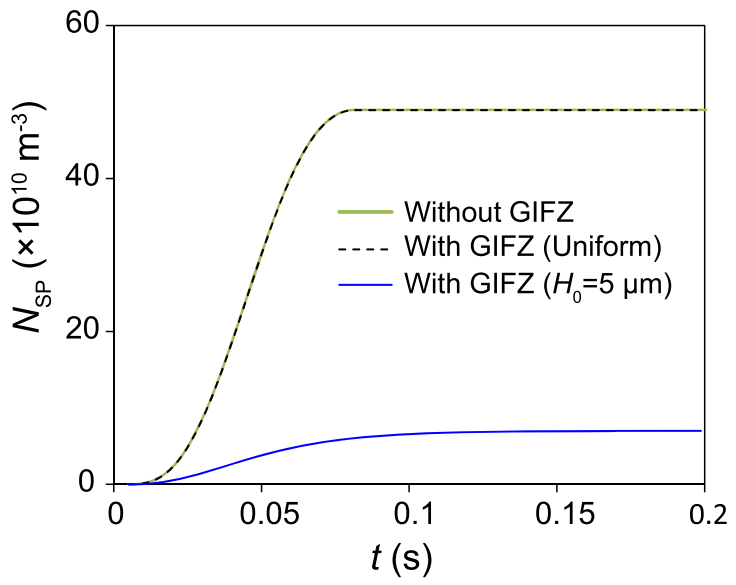

(b)

Fig. 4 - Calculated $(a)$ cooling curves and $(b)$ the total number density of solid particles $\left(N_{\mathrm{SP}}\right)$ with and without consideration of GIFZ for Al-1Cu alloy with $N_{0}=10^{13} \mathrm{~m}^{-3}$ and $\dot{T}=3.5 \mathrm{~K} / \mathrm{s}$ (Color figure online).

means that the solid particles become more uniform in size when both GIFZ and nucleant particle agglomeration are considered during the calculation.

We have investigated the effect of nucleant particle agglomeration measured by the geometric mean particle separation $\left(H_{0}\right)$ on various microstructural parameters, such as the final grain size $(d)$, solid particle radius $\left(R_{\mathrm{s}}\right)$, the fraction of solid $\left(f_{\mathrm{s}}\right)$ and the normalised GIFZ size $\left(R_{\mathrm{GIFZ}} / H_{0}\right)$ at the point of recalescence, and the calculated results are presented in Figure 6 as a function of the geometric mean of nucleant particle separation. Figure 6(a) shows that the final grain size decreases sharply with the increase of $H_{0}$ (i.e., decreasing degree of particle agglomeration), levels off at higher $H_{0}$ and becomes a constant when the nucleant particle distribution becomes uniform $\left(U_{0}=46 \mu \mathrm{m}\right.$ in this case). This same trend is also found for solid particle size (Figure 6(b)) and the fraction of the solid (Figure 6(c)) at recalescence. When nucleant particles have severe agglomeration (approximately $H_{0}<2 R_{\mathrm{GIFZ}}$ as shown in Figure 6(d)), increasing particle agglomeration decreases solid particle number density $\left(N_{\mathrm{sp}}\right)$ and increase solid particle size $\left(R_{\mathrm{s}}\right)$ and the fraction of solid $\left(f_{\mathrm{s}}\right)$ at recalescence. However, when the nucleant particles have less severe agglomeration $\left(H_{0}>2 R_{\mathrm{GIFZ}}\right)$, particle agglomeration has little effect on all these microstructural parameters.

Re-melting of solid particles is another reason for the potential increase in grain size. Figure 7 demonstrates the effect of solid particle re-melting on grain size. For a 


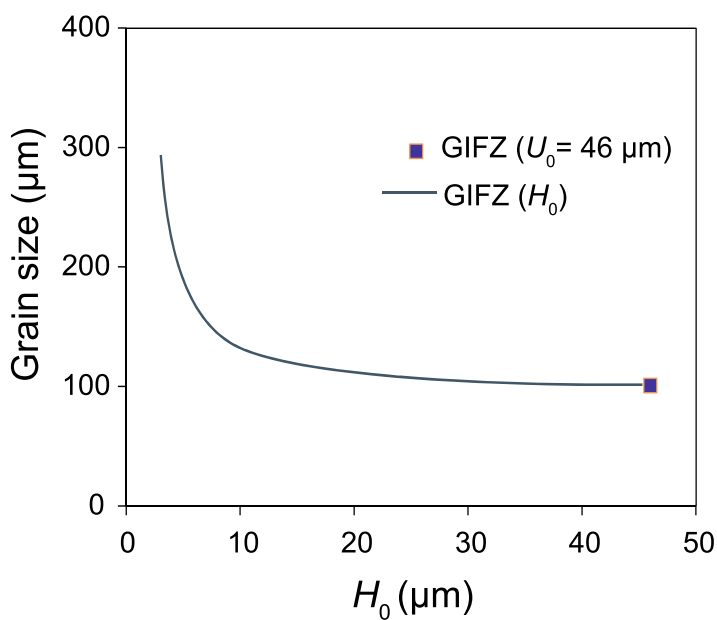

(a)

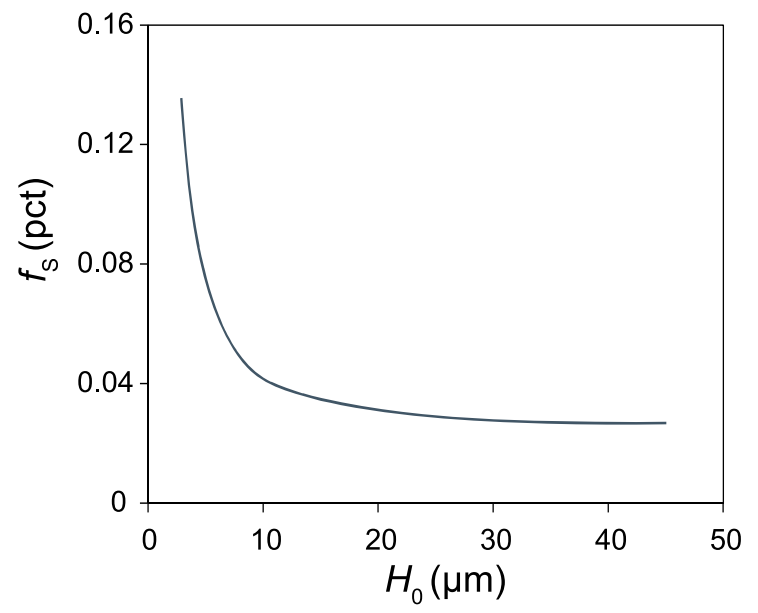

(c)

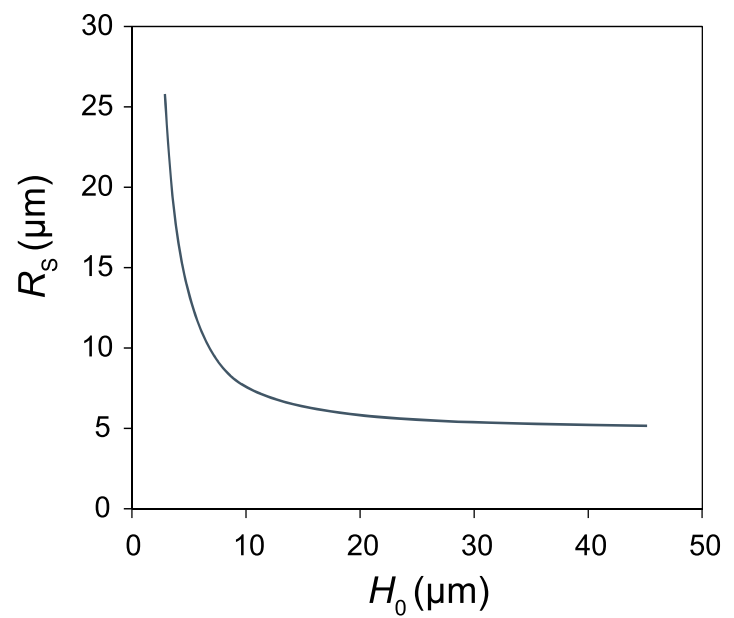

(b)

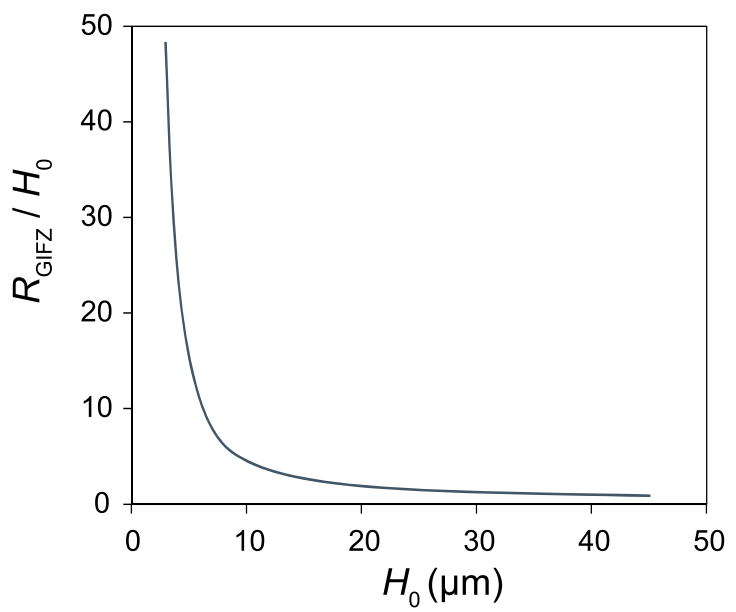

(d)

Fig. 6-Effect of nucleant particle agglomeration (measured by the mode of nucleant particle separation, $\left.H_{0}\right)$ on $(a)$ grain size, $(b)$ solid particle size $\left(R_{\mathrm{s}}\right),(c)$ fraction of the solid $\left(f_{\mathrm{s}}\right)$, and $(d)$ normalised GIFZ size by the geometric mean of nucleant particle separation $\left(R_{\mathrm{GIFZ}} / H_{0}\right)$ at recalescence during solidification of $\mathrm{Al}-1 \mathrm{Cu}$ alloy with $N_{0}=10^{13} \mathrm{~m}^{-3}$ and $\dot{T}=3.5 \mathrm{~K} / \mathrm{s} . U_{0}=46 \mu \mathrm{m}$ is the nucleant particle separation with a uniform particle distribution and $N_{0}=10^{13} \mathrm{~m}^{-3}$.

uniform distribution of nucleant particles, the re-melting effect is negligible regardless of the solute concentration, as demonstrated by the overlap between the solid line (without consideration of re-melting) and the filled squares (with consideration of re-melting). The effect of particle re-melting only becomes visible when the nucleant particle agglomeration becomes severe and the solute concentration is high, i.e., $H_{0}<5 \mu \mathrm{m}$ and $C_{0}(\mathrm{Cu})>3 \mathrm{wt}$ pct, as shown in Figure 7 by the separation between the dotted line and the filled circles.

As re-melting of solid particles is more relevant to the GIFZ size $\left(R_{\mathrm{GIFZ}}\right)$ and the mean solid particle separation $\left(S_{0}\right)$, the re-melting effect on grain size should only be visible when the GIFZ size becomes comparable with the mean solid particle separation. Figure 8 shows the normalised GIFZ size by the mean solid particle separation $\left(R_{\mathrm{GIFZ}} / S_{0}\right)$ as a function of solute concentration and degree of agglomeration of nucleant particles. It is clear from Figure 8 that $R_{\mathrm{GIFZ}} / S_{0}$ is always less than 1 within the space of considerations, suggesting that the GIFZ size is always smaller than the mean solid particle separation regardless of the $\mathrm{Cu}$ concentration and the degree of nucleant particle agglomeration. Therefore, there is little possibility for overlap between the GIFZ of growing solid particles, and hence solid particle re-melting becomes a low probability event and can be ignored during modelling of solidification processes.

The effect of solute concentration on grain size with varying degrees of nucleant particle agglomeration has been investigated numerically in this work. To demonstrate the solute concentration effect, the ratio of the total number density of solid particles with agglomeration to that without agglomeration (uniform distribution), $N_{\mathrm{SP}}\left(H_{0}\right) / N_{\mathrm{SP}}\left(U_{0}\right)$, is used to demonstrate the effectiveness of nucleant particle agglomeration on grain size, and the results are shown in Figure 9(a). For a given level of particle agglomeration, the value of $N_{\mathrm{SP}}\left(H_{0}\right) / N_{\mathrm{SP}}\left(U_{0}\right)$ only has a slight change with increasing $\mathrm{Cu}$ concentration. Figure 9(a) suggests that for a 
given degree of nucleant particle agglomeration solute concentration has very little effect on solid particle number density and thus little effect on grain size.

Taking $H_{0}=5 \mu \mathrm{m}$ for example, the effectiveness of agglomeration on grain size is almost constant since the predicted grain size with agglomeration (e.g., $H_{0}=5$ $\mu \mathrm{m})$ is more or less parallel to that without agglomeration in the range of $\mathrm{Cu}$ concentration considered (see Figure 3). Here we demonstrate the influence of $\mathrm{Cu}$ concentration on $R_{\mathrm{GIFZ}} / H_{0}$ when $H_{0}=5 \mu \mathrm{m}$ in Figure 9(b). With increasing $\mathrm{Cu}$ concentration (from 1 to $10 \mathrm{wt}$ pct), $R_{\mathrm{GIFZ}} / H_{0}$ does not change so significantly and remains high (between 15 and 10). Therefore, the effectiveness of particle agglomeration on grain size is almost the same for alloys with different $\mathrm{Cu}$ content.

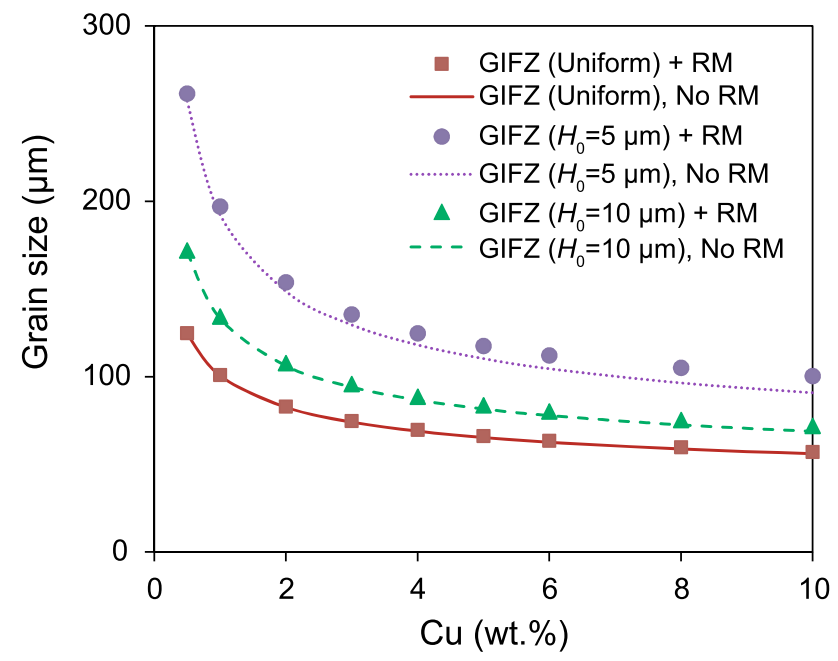

Fig. 7-Calculated grain size with and without consideration of solid particle re-melting (RM) for Al-Cu alloys with $N_{0}=10^{13} \mathrm{~m}^{-3}$ and $\dot{T}=3.5 \mathrm{~K} / \mathrm{s}$, showing that under solidification conditions relevant to industrial practice the influence of solid particle re-melting on grain size is very limited and can be therefore ignored during theoretical analysis.

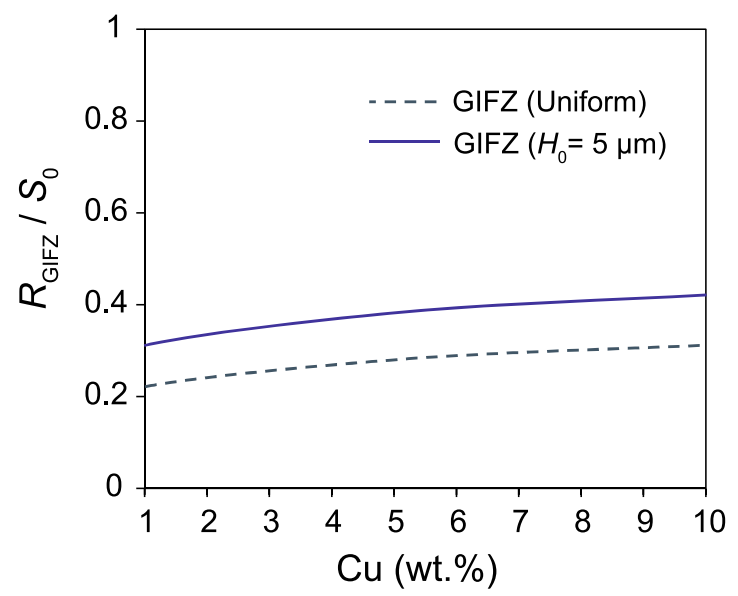

(a)
Moreover, when nucleant particles are distributed uniformly in the melt, $R_{\mathrm{GIFZ}} / H_{0}$ has little change and remains less than 1 for $\mathrm{Cu}$ concentration between 1 to 10 wt pct (Figure 9(b)). This suggests that when nucleant particles have a uniform distribution the GIFZ does not affect grain size regardless of solute concentration, being consistent with the results in Figure 3.

The effect of cooling rate on the grain size of $\mathrm{Al}-1 \mathrm{Cu}$ alloy containing $\mathrm{TiB}_{2}$ particles with $N_{0}=10^{13} \mathrm{~m}^{-3}$ is shown in Figure 10(a). From Figure 10(a), it is noted that the agglomeration effect on grain size is only significant at a low cooling rate. For instance, at a cooling rate of $1 \mathrm{~K} / \mathrm{s}$, grain size increases from $141 \mu \mathrm{m}$ for uniform particle distribution to $305 \mu \mathrm{m}$ with $H_{0}=5$ $\mu \mathrm{m}$. However, at the high cooling rate, this effect becomes much less. For example, the grain size is only increased from $39 \mu \mathrm{m}$ with uniform particle distribution to $52 \mu \mathrm{m}$ with $H_{0}=5 \mu \mathrm{m}$ at a cooling rate of $1000 \mathrm{~K} / \mathrm{s}$. The effect of the cooling rate can be understood by the decreased $R_{\mathrm{GIFZ}} / H_{0}$ in Figure $10(\mathrm{~b})$ and the increase in $R_{\mathrm{GIFZ}} / S_{0}$ in Figure $10(\mathrm{c})$. With increasing cooling rate, the decrease in $R_{\mathrm{GIFZ}} / H_{0}$ (Figure $10(\mathrm{~b})$ ) reduces the effect of agglomeration and hence increases the number of grain initiation events, whilst the limited increase in $R_{\mathrm{GIFZ}} / S_{0}$ (Figure 10(c)) means that the increase in re-melting of solid particles will be insignificant.

The effect of nucleant particle number density on grain size with consideration of agglomeration was also investigated and the results are presented in Figure 11(a). The nucleant particle number density is changed from $10^{12}$ to $10^{15} \mathrm{~m}^{-3}$, corresponding to changes of grain refiner addition level from 0.02 to 20 wt pet of commercial Al-5Ti-1B grain refiner. Similar to the cooling rate effect, particle agglomeration has a stronger effect on grain size at low particle number density than that at high particle number density. For instance, at low nucleant particle density (e.g., $N_{0}=$ $\left.10^{12} \mathrm{~m}^{-3}\right)$, the grain size is increased significantly from $148 \mu \mathrm{m}$ for uniform particle distribution to $398 \mu \mathrm{m}$ for $H_{0}=5 \mu \mathrm{m}$; in contrast, at high particle density (e.g., $N_{0}$

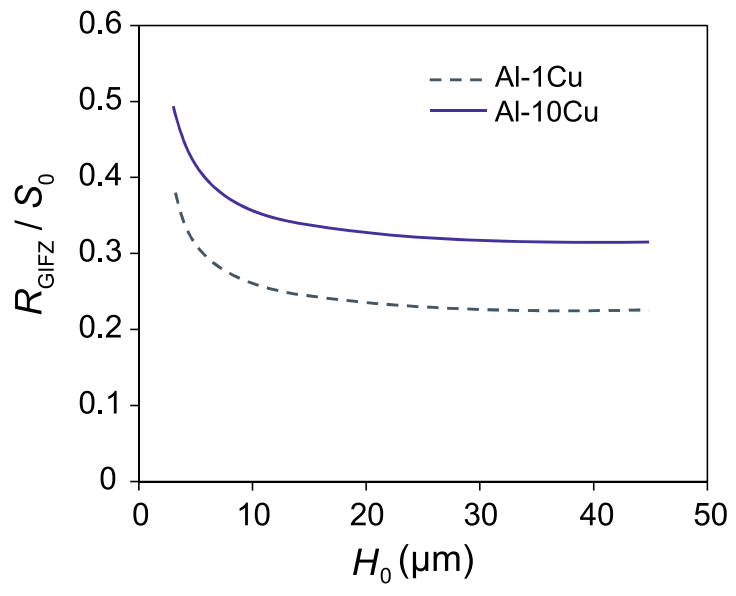

(b)

Fig. 8-Effect of $(a)$ solute concentration and $(b)$ geometric mean of nucleant particle separation $\left(H_{0}\right)$ on the normalised GIFZ size by the mean solid particle separation $\left(R_{\mathrm{GIFZ}} / S_{0}\right)$ at recalescence during solidification of $\mathrm{Al}-\mathrm{Cu}$ alloys with $N_{0}=10^{13} \mathrm{~m}^{-3}$ and $\dot{T}=3.5 \mathrm{~K} / \mathrm{s}$. 


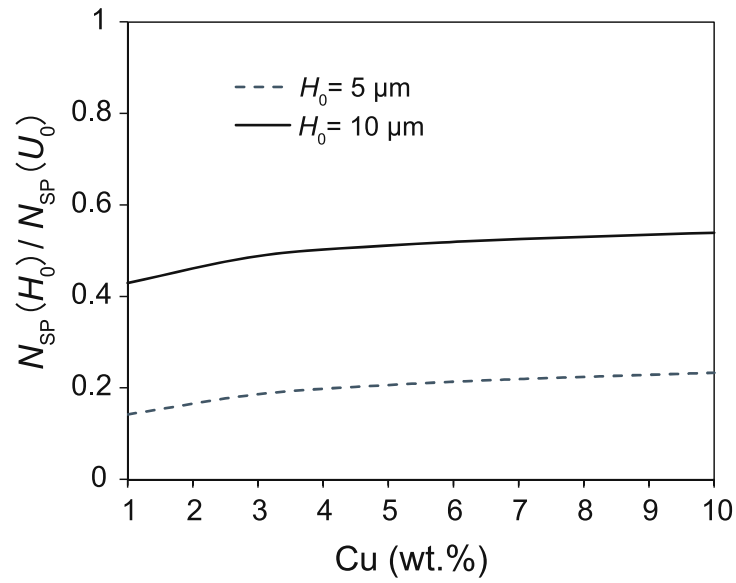

(a)

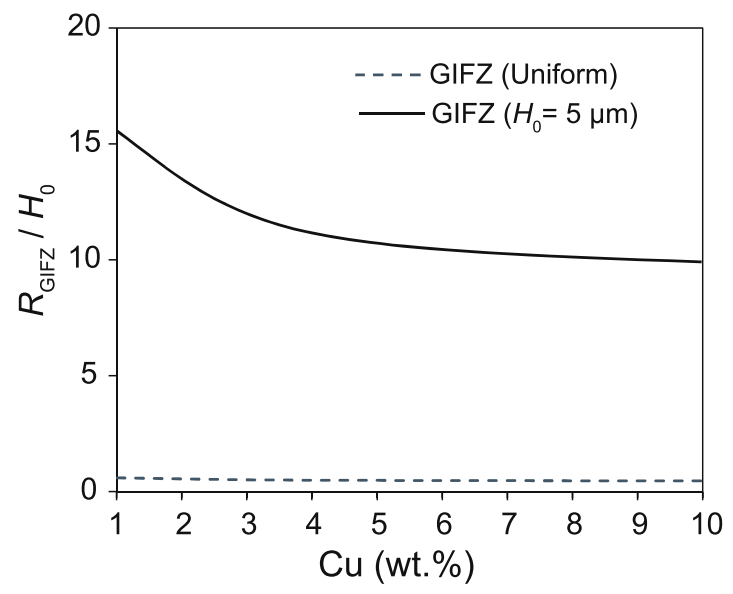

(b)

Fig. 9-Effect of solute concentration on (a) normalised number density of solid particles with and without particle agglomeration $\left(N_{\mathrm{SP}}\left(H_{0}\right) /\right.$ $\left.N_{\mathrm{SP}}\left(U_{0}\right)\right)$ and $(b)$ normalised GIFZ size by the geometric mean of nucleant particle separation $\left(R_{\mathrm{GIFZ}} / H_{0}\right)$ during solidification of Al-Cu alloys with $N_{0}=10^{13} \mathrm{~m}^{-3}$ and $\dot{T}=3.5 \mathrm{~K} / \mathrm{s}$.

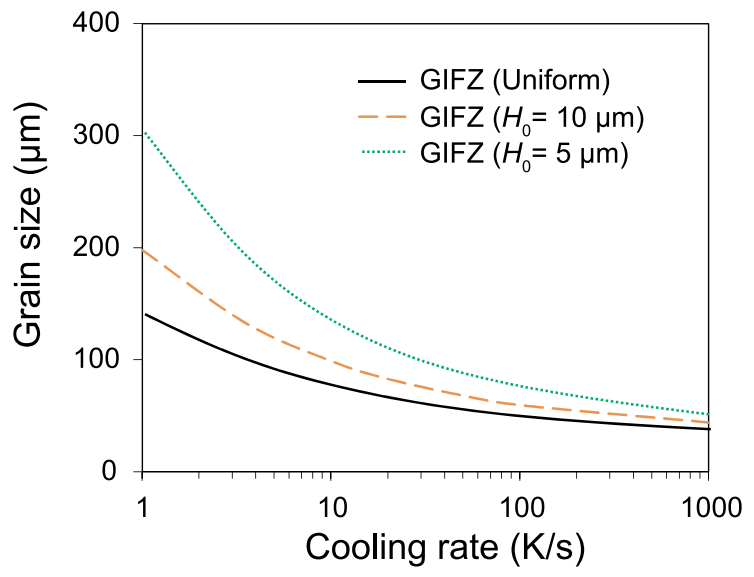

(a)

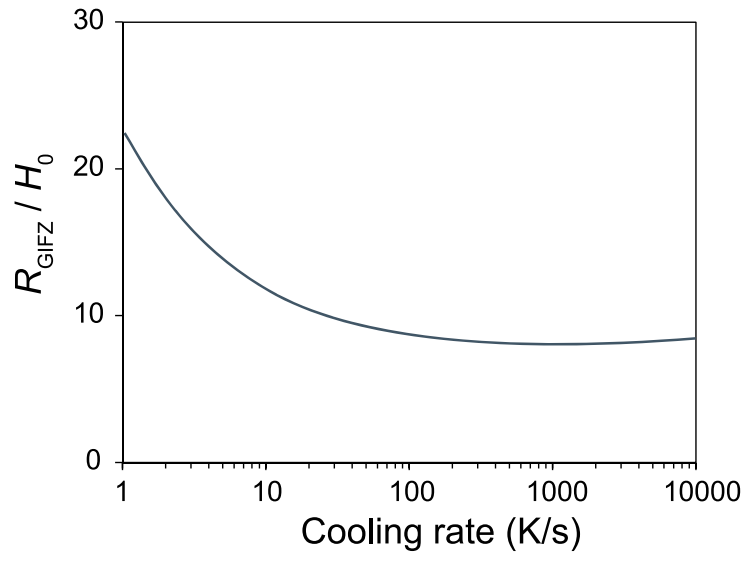

(b)

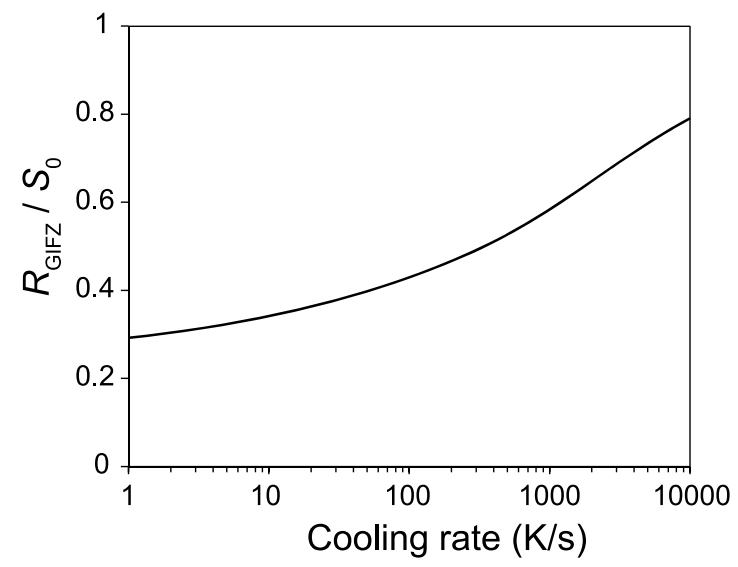

(c)

Fig. 10-Effect of cooling rate on $(a)$ grain size, $(b)$ normalised GIFZ size by the geometric mean of nucleant particle separation $\left(R_{\mathrm{GIFZ}} / H_{0}\right)$, and $(c)$ normalised GIFZ size by the mean solid particle separation $\left(R_{\mathrm{GIFZ}} / S_{0}\right)$ during solidification of Al-1Cu alloys with $N_{0}=10^{13} \mathrm{~m}^{-3} ;$ for $(\mathrm{b}, \mathrm{c})$ the $H_{0}=5 \mu \mathrm{m}$. 


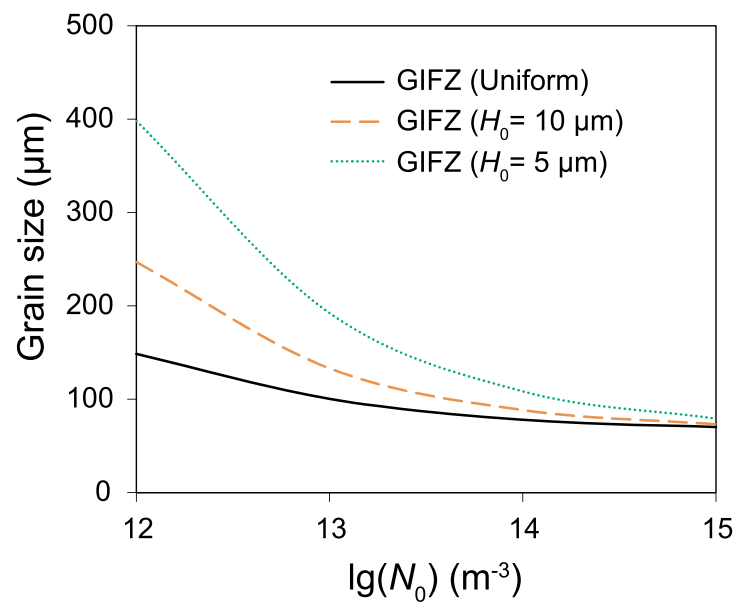

(a)

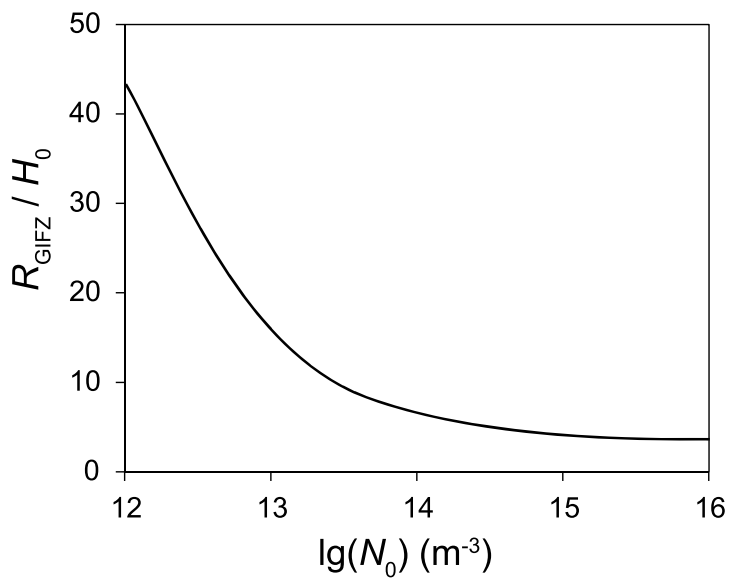

(c)

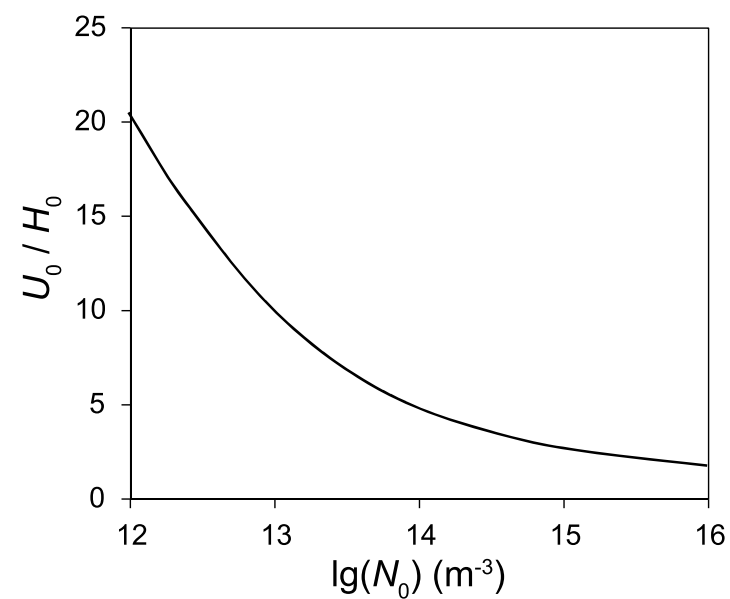

(b)

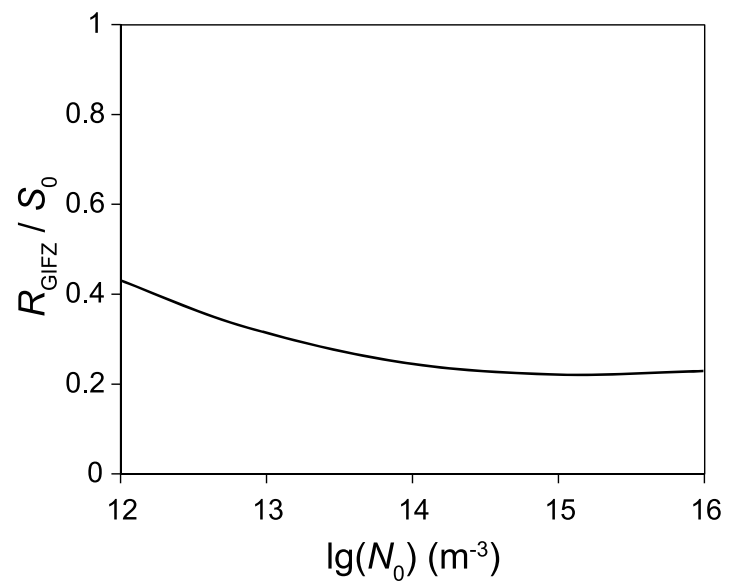

(d)

Fig. 11-Effect of number density of nucleant particles on $(a)$ grain size, $(b)$ the ratio of nucleant particle separations with and without particle agglomeration, $(c)$ normalised GIFZ size by the geometric mean of nucleant particle separation $\left(R_{\mathrm{GIFZ}} / H_{0}\right)$, and $(d)$ normalised GIFZ size by mean solid particle separation $\left(R_{\mathrm{GIFZ}} / S_{0}\right)$ for Al-1Cu alloys with $\dot{T}=3.5 \mathrm{~K} / \mathrm{s}$; for (b-d) $H_{0}=5 \mu \mathrm{m}$.

$\left.=10^{15} \mathrm{~m}^{-3}\right)$, the grain size is only increased from $70 \mu \mathrm{m}$ for uniform particle distribution to $79 \mu \mathrm{m}$ for $H_{0}=5$ $\mu \mathrm{m}$ (see Figure 11(a)). This trend agrees with experimental data ${ }^{[40]}$ Such effect of nucleant particle number density can be attributed to the change towards uniform particle distribution with increasing particle number density, i.e., $H_{0} \rightarrow U_{0}$, or $U_{0} / H_{0} \rightarrow 1$ (Figure 11(b)). This effect can be further understood by the effect of particle number density on the normalised GIFZ size:

(1) as shown in Figure 11(c), the normalised GIFZ size by the geometric mean of nucleant particle separation $\left(R_{\mathrm{GIFZ}} / H_{0}\right)$ decreases with increasing particle number density $\left(N_{0}\right)$ and levels off at high $N_{0}$. This suggests that the probability of nucleant particles located in the GIFZ becomes less with increasing $N_{0}$, and thus less effect of agglomeration on grain size; and

(2) the normalised GIFZ size by the mean solid particle separation $\left(R_{\mathrm{GIFZ}} / S_{0}\right)$ has little change and remains relatively constant (Figure 11(d)), suggesting that increasing particle number density has little effect on solid particle re-melting and hence the little effect on grain size.

\section{DISCUSSIONS}

Grain refinement is a complex phenomenon, involving a number of physical processes and being affected by many parameters. ${ }^{[24]}$ The physical processes involved include heterogeneous nucleation, ${ }^{[24]}$ grain initiation, ${ }^{[9,23]}$ crystal growth, ${ }^{[48]}$ columnar to equiaxed transition ${ }^{[14,49,50]}$ and more. The parameters that affect grain refinement may include solute elements (nature of solutes, solute concentration, and interaction between solutes), nucleant particles (nucleation potency $\left(\Delta T_{n}\right),{ }^{[23,24]}$ particle size and size distribution, ${ }^{[41]}$ degree of particle agglomeration) and solidification conditions (e.g., cooling rate). Amongst these parameters, nucleant particle agglomeration is the least studied in the literature and has been the subject of this paper. 
For isothermal solidification, it is generally accepted that the arising temperature due to recalescence will cease any further grain initiation and the final grain size is determined by the total number of initiated grains at the time of recalescence $\left(N_{\mathrm{g}}\right)$ based on Eq. [6]. However, the nucleant particles are usually assumed to have a uniform distribution and the predicted grain size is considerably smaller than the experimental data (Figure 3). Shu et al. ${ }^{[15]}$ speculated that the existence of the SSN zone is the main reason for such discrepancy between experimental data and theoretical predictions. However, the SSN effect in Reference 15 was overestimated as the size of SSN is significantly exaggerated. ${ }^{[16,22]}$ In fact, SSN has much less effect on grain size, ${ }^{[16]}$ which has been confirmed by the numerical analysis in this work (Figure 3) when the distribution of nucleant particles is assumed to be uniform. For uniform particle distribution the particle separation is a constant $\left(U_{0}\right)$ and can be obtained from Eq. [3], for example, $U_{0}=46 \mu \mathrm{m}$ for $N_{0}=10^{13} \mathrm{~m}^{-3}$. From our calculation, the discrepancy between the theoretical predictions and the experimental data is attributed to the agglomeration of nucleant particles, as shown in Figure 3, where the degree of agglomeration strongly affects the final grain size when the GIFZ is considered. We found that grain size decreases with decreasing degree of particle agglomeration, i.e., with increasing $H_{0}$ (Figure 6(a)).

As presented in Section III, the GIFZ effect on grain size is only of significance when there is a particular agglomeration, which reduces the effective number of nucleant particles. For example, in the study of $\mathrm{Xu}$ et al. ${ }^{[18]}$ particle number density used is $2.5 \times 10^{11} \mathrm{~m}^{-3}$ for 0.1 wt pct addition of $\mathrm{Al}-5 \mathrm{Ti}-1 \mathrm{~B}$ grain refiner, which was determined by tuning of solidification sequence of $\mathrm{Al}-10 \mathrm{Cu}$ alloy with addition of $0.05 \mathrm{wt}$ pet $\mathrm{Al}-5 \mathrm{Ti}-1 \mathrm{~B}$ solidified under $0.5 \mathrm{~K} / \mathrm{s}$ cooling rate. This number density is much smaller than that $7.2 \times 10^{12} \mathrm{~m}^{-3}$ used by Quested and Greer. ${ }^{[41]}$ As the number density is inferred from the experimental result, ${ }^{[18]}$ the effect of particle agglomeration has been taken into consideration although unintentionally.

In this work, we have systematically assessed the effect of nucleant particle agglomeration on grain size by introducing the concepts of GIFZ and re-melting of solid particles. Building on the work in the literature, this work has led to an improved understanding of the CS zone on grain size, which can be summarised as follows:

- Growth restriction The CS zone decreases the growth velocity of the solid through growth restriction, which allows more nucleant particles to participate in grain initiation and gives rise to a reduced grain size $^{[51]}$ although this effect is very limited. ${ }^{[47,52]}$

- GIFZ In the presence of nucleant particle agglomeration, GIFZ reduces the number density of initiated solid particles and hence increases the grain size, depending on the relative position of GIFZ size $\left(R_{\mathrm{GIFZ}}\right)$ to the geometric mean of nucleant particle separation $\left(H_{0}\right)$. To a good approximation, when $H_{0}$ $>2 R_{\mathrm{GIFZ}}$, particle agglomeration has limited influence on grain size; when $H_{0}<2 R_{\mathrm{GIFZ}}$, particle agglomeration has a significant effect on grain size.

- Re-melting of initiated solid particles Re-melting of solid particles also reduces the number density of initiated solid particles and thus increases the grain size, depending on the relative position of GIFZ size $\left(R_{\mathrm{GIFZ}}\right)$ to the mean solid particle separation $\left(S_{0}\right)$. When $S_{0}>2 R_{\mathrm{GIFZ}}$, particle agglomeration has limited influence on grain size; when $S_{0}<2 R_{\mathrm{GIFZ}}$, particle agglomeration has some effect on grain size although this effect is limited and can be ignored under solidification conditions relevant to industrial practice.

This work also has practical implications for grain refinement. Our numerical analysis suggests that decreasing the level of nucleant particle agglomeration can effectively increase the number density of initiated grains and thus decrease grain size (Figure 6). Therefore, any practical approach that can reduce the degree of nucleant particle agglomeration can improve grain refinement.

As suggested in References 39, 53, the $\mathrm{TiB}_{2}$ particle agglomerates are very hard to disperse during the normal melting and solidification process, meaning that $\mathrm{TiB}_{2}$ particle agglomeration is widely present. This phenomenon is not only applicable to $\mathrm{TiB}_{2}$ particles but also to other grain refiners or oxides. Therefore, techniques for effective dispersion of nucleant particles are necessary for grain refinement, such as intensive melt shearing technique ${ }^{[54-56]}$ and ultrasonic melt treatment technique. ${ }^{[57,58]}$ For example, after 1 minute of ultrasonic treatment of the re-melted commercial Al-5Ti-1B grain refiner at $750{ }^{\circ} \mathrm{C}$, the size of clusters of $\mathrm{TiB}_{2}$ particles is decreased and more uniformly distributed compared with that without ultrasonic treatment. ${ }^{[36]}$ Consequently, the average grain size of CP-Al is decreased from $228 \mu \mathrm{m}$ (with untreated grain refiner) to $198 \mu \mathrm{m}$ (with ultrasonically treated grain refiner). ${ }^{[36]}$ When the ultrasonic treatment is applied during the production of Al-5Ti-1B grain refiner, the grain size of $\mathrm{CP}-\mathrm{Al}$ is decreased to $100 \mu \mathrm{m}$ with $0.2 \mathrm{wt}$ pet addition of newly produced $\mathrm{Al}-5 \mathrm{Ti}-1 \mathrm{~B}$ grain refiner, although particle agglomeration still exists in the newly produced $\mathrm{Al}-5 \mathrm{Ti}-1 \mathrm{~B}$ grain refiner. ${ }^{[36,37]}$ Intensive melt shearing is another effective technique to disperse nucleant particles, such as oxides in $\mathrm{Al}$ and $\mathrm{Mg}$ alloys. ${ }^{[54-56]}$ Fan et al. ${ }^{[59]}$ found experimentally that a significant grain refinement of the primary $\alpha-\mathrm{Mg}$ is achieved by applying intensive melt shearing to AZ91D alloy melt prior to solidification processing. The main reason is that intensive melt shearing can effectively disperse the oxide films into individual $\mathrm{MgO}$ particles that can act as potent nucleation sites for $\alpha-\mathrm{Mg} .{ }^{[59]}$ For instance, the $\mathrm{MgO}$ particle number density can be increased to $10^{17} \mathrm{~m}^{-3}$ by intensive melt shearing from $10^{14} \mathrm{~m}^{-3}$ without melt shearing in AZ91D alloy. ${ }^{[60]}$ Similarly, application of extensive melt shearing in other Al- and $\mathrm{Mg}$ alloys ${ }^{[54,61-65]}$ has resulted in significant grain refinement, which is comparable to that achieved by the addition of grain refiners without melt shearing. 


\section{CONCLUSIONS}

In this work, we have systematically assessed the effect of nucleant particle agglomeration on the grain size by introducing two mechanisms that are related to the constitutionally supercooled (CS) zone around a growing solid particle. One is the GIFZ that describes the inability for grain initiation in the CS zone, and the other one is re-melting of initiated grains due to the overlap of the CS zones. The following conclusions can be drawn from our numerical analysis:

(1) Without consideration of the GIFZ, this and other numerical models in the literature underestimate significantly the solidified grain size compared with the experimental data. The predicted grain size is usually about $50 \mathrm{pct}$ of the experimental data under the TP-1 test condition (cooling rate is $3.5 \mathrm{~K} / \mathrm{s}$ ).

(2) Without considering nucleant particle agglomeration (i.e., assuming a uniform distribution) the GIFZ has no effect on grain size during solidification under conditions relevant to the industrial practice since the nucleant particle separation with a uniform distribution is usually larger than the size of the GIFZ.

(3) Grain size can only be predicted with reasonable accuracy when both the GIFZ and nucleant particle agglomeration are considered simultaneously. Under the TP-1 solidification condition with grain refiner addition, nucleant particle agglomeration is responsible for the loss of $7 / 8$ grain initiation events that would occur when nucleant particles have a uniform distribution.

(4) Both cooling rate and nucleant particle number density similarly affect grain size depending on the relative position of GIFZ size $\left(R_{\mathrm{GIFZ}}\right)$ to the geometric mean of nucleant particle separation $\left(H_{0}\right)$. When $H_{0}>2 R_{\mathrm{GIFZ}}$, both cooling rate and nucleant particle number density have a limited influence on grain size. When $H_{0}<2 R_{\mathrm{GIFZ}}$, their effect will be significant; increasing cooling rate and/or nucleant particle number density will lead to a reduction in grain size.

(5) Under normal solidification conditions relevant to industrial practice, re-melting of solid particles due to the overlap of the CS zones have little effect on grain size and may be ignored during theoretical analysis.

\section{ACKNOWLEDGMENTS}

Financial support from the EPSRC (UK) under Grant Number EP/N007638/1 is gratefully acknowledged.

\section{CONFLICT OF INTEREST}

On behalf of all authors, the corresponding author states that there is no conflict of interest.

\section{OPEN ACCESS}

This article is licensed under a Creative Commons Attribution 4.0 International License, which permits use, sharing, adaptation, distribution and reproduction in any medium or format, as long as you give appropriate credit to the original author(s) and the source, provide a link to the Creative Commons licence, and indicate if changes were made. The images or other third party material in this article are included in the article's Creative Commons licence, unless indicated otherwise in a credit line to the material. If material is not included in the article's Creative Commons licence and your intended use is not permitted by statutory regulation or exceeds the permitted use, you will need to obtain permission directly from the copyright holder. To view a copy of this licence, visit http://creat ivecommons.org/licenses/by/4.0/.

\section{REFERENCES}

1. M. Easton and D. StJohn: Metall. Mater. Trans. A, 1999, vol. 30A, pp. 1613-23.

2. T.E. Quested: Mater. Sci. Technol., 2004, vol. 20, pp. 1357-69.

3. A.L. Greer: J. Chem. Phys., 2016, vol. 145, p. 211704.

4. M.A. Easton, M. Qian, A. Prasad, and D.H. StJohn: Curr. Opin. Solid State Mater. Sci., 2016, vol. 20, pp. 13-24.

5. Z. Liu: Metall. Mater. Trans. A, 2017, vol. 48A, pp. 4755-76.

6. M.A. Easton, A. Prasad, D. Qiu, M.A. Gibson, M. Qian, M. Brandt, G. Wang, and D.H. St John: SP17-Solidification Processing 2017. Old Windsor, UK, July 2017, pp. 87-90.

7. W.A. Tiller, K.A. Jackson, J.W. Rutter, and B. Chalmers: Acta Metall., 1953, vol. 4, pp. 428-37.

8. I. Maxwell and A. Hellawell: Acta Metall., 1975, vol. 23, pp. 229-37.

9. A.L. Greer, A.M. Bunn, A. Tronche, P.V. Evans, and D.J. Bristow: Acta Mater., 2000, vol. 48, pp. 2823-35.

10. J.W. Rutter and B. Chalmers: Can. J. Phys., 1953, vol. 31, pp. 15-39.

11. W. Winegard and B. Chalmers: Trans. ASM, 1954, vol. 46, pp. 1214-24

12. M. Qian, P. Cao, M.A. Easton, S.D. McDonald, and D.H. StJohn: Acta Mater., 2010, vol. 58, pp. 3262-70.

13. D.H. StJohn, M. Qian, M.A. Easton, and P. Cao: Acta Mater., 2011, vol. 59, pp. 4907-21.

14. E. Quested and A.L. Greer: Acta Mater., 2005, vol. 53, pp. 4643-53.

15. D. Shu, B. Sun, J. Mi, and P.S. Grant: Acta Mater., 2011, vol. 59, pp. $2135-44$.

16. Q. Du and Y. Li: Acta Mater., 2014, vol. 71, pp. 380-389.

17. A. Prasad, L. Yuan, P.D. Lee, and D.H. StJohn: Acta Mater., 2013, vol. 61, pp. 5914-27.

18. Y. Xu, D. Casar, Q. Du, R.H. Mathiesen, L. Arnberg, and Y. Li: Acta Mater., 2017, vol. 140, pp. 224-39.

19. Y. Xu, D. Casari, R.H. Mathiesen, and Y. Li: Acta Mater., 2018, vol. 149, pp. 312-25.

20. E. Liotti, C. Arteta, A. Zisserman, A. Lui, V. Lempitsky, and P.S. Grant: Sci. $A d v$., 2018, vol. 4, p. eaar4004. 
21. Y. Jia, H. Huang, Y. Fu, G. Zhu, D. Shu, B. Sun, and D.H. StJohn: Sci. Mater., 2019, vol. 167, pp. 6-10.

22. D.H. StJohn, A. Prasad, M.A. Easton, and M. Qian: Metall. Mater. Trans. A, 2015, vol. 46A, pp. 4868-85.

23. Z. Fan, F. Gao, B. Jiang, and Z.P. Que: Sci. Rep., 2020, vol. 10, p. 9448.

24. Z. Fan: Metall. Mater. Trans. A, 2013, vol. 44A, pp. 1409-18.

25. Z. Fan and H. Men: Mater. Res. Express, 2020, vol. 7, p. 126501.

26. H. Men and Z. Fan: Metall. Mater. Trans. A, 2018, vol. 49A, pp. $2766-77$.

27. B. Jiang, H. Men, and Z. Fan: Comput. Mater. Sci., 2018, vol. 153, pp. 73-81.

28. C.M. Fang and Z. Fan: Metall. Mater. Trans. A, 2020, vol. 51A, pp. 788-97.

29. C.M. Fang and Z. Fan: Comput. Mater. Sci., 2020, vol. 171, p. 109258.

30. C.M. Fang, H. Men, and Z. Fan: Metall. Mater. Trans. A, 2018, vol. 49A, pp. 6231-42.

31. S.R. Bakshi, D. Lahiri, and A. Agarwal: Int. Mater. Rev., 2010, vol. 55, pp. 41-64.

32. D.J. Lloyd: Int. Mater. Rev., 1994, vol. 39, pp. 1-23.

33. Y. Yashpal, A. Sumankant, C.S. Jawalkar, A.S. Verma, and N.M. Suri: Mater. Today, 2017, vol. 4, pp. 2927-36.

34. S. Sardar, S.K. Karmakar, and D. Das: Mater. Today, 2017, vol. 4, pp. 3280-89.

35. I.G. Watson, M.F. Forster, P.D. Lee, R.J. Dashwood, R.W. Hamilton, and A. Chirazi: Composite A, 2005, vol. 36, pp. $1177-87$.

36. Y. Han, K. Li, J. Wang, D. Shu, and B. Sun: Mater. Sci. Eng. A, 2005, vol. 405, pp. 306-12.

37. Y. Han, D. Shu, J. Wang, and B. Sun: Mater. Sci. Eng. A, 2006, vol. 430, pp. 326-31.

38. Y. Jia, D. Wang, Y. Fu, A. Dong, G. Zhu, D. Shu, and B. Sun: Metall. Mater. Trans. A, 2019, vol. 50, pp. 1795-1804.

39. E.J. Asbjornsson: PhD thesis, University of Nottingham, 2001.

40. J. Xu, R. Li, and Q. Li: Metall. Mater. Trans. A, 2021, vol. 52A, pp. 1077-94.

41. T.E. Quested and A.L. Greer: Acta Mater., 2004, vol. 52, pp. 3859-68.

42. Z. Fan, H. Men, Y. Wang, and Z. Que: Metals, 2021, vol. 11, p. 478.

43. Z. Fan, Y. Wang, Y. Zhang, T. Qin, X.R. Zhou, G.E. Thompson, T. Pennycook, and T. Hashimoto: Acta Mater., 2015, vol. 84, pp. 292-304.

44. W. Yang, L. Liu, J. Zhang, S. Ji, and Z. Fan: Mater. Lett., 2015, vol. 160 , pp. 263-67.

45. S. Wang, Y. Wang, Q. Ramasse, and Z. Fan: Metall. Mater. Trans. A, 2020, vol. 51A, pp. 2957-74.
46. J.A. Spittle and S.B. Sadli: Mater. Sci. Technol., 1995, vol. 11, pp. 533-37.

47. Z. Fan, F. Gao, Y. Wang, and L. Zhou: Effect of solutes on grain refinementProgr. Mater. Sci., 2021, vol. 123, p. 100809.

48. R. Willnecker, D.M. Herlach, and B. Feuerbacher: Appl. Phys. Lett., 1990, vol. 56, pp. 324-26.

49. D.G. McCartney: Inter. Mater. Rev., 1989, vol. 34, pp. 247-60.

50. L. Sturz, A. Drevermann, C. Pickmann, and G. Zimmermann: Mater. Sci. Eng. A, 2005, vol. 413, pp. 379-83.

51. H. Men and Z. Fan: Acta Mater., 2011, vol. 59, pp. 2704-12.

52. Z. Fan, F. Gao, L. Zhou, and S.Z. Lu: Acta Mater., 2018, vol. 152, pp. 248-57.

53. B. Cantor and M.J. Goringe: Solidification and casting, The Institute of Physics, London, 2003.

54. Z. Fan, Y. Wang, Z.F. Zhang, M. Xia, H.T. Li, J. Xu, L. Granasy, and G.M. Scamans: Inter. J. Cast Metals Res., 2009, vol. 22, pp. $318-22$.

55. Z. Fan, M. Xia, H. Zhang, G. Liu, J.B. Patel, Z. Bian, I. Bayandorian, Y. Wang, H.T. Li, and G.M. Scamans: Inter. J. Cast Metals Res., 2009, vol. 22, pp. 103-07.

56. J.B. Patel, X. Yang, C.L. Mendis, and Z. Fan: JOM, 2017, vol. 69 , pp. 1071-76

57. G.I. Eskin: Ultrasonic Treatment of Light Alloy Melts, Gordon \& Breach, Amsterdam, 1998.

58. G.I. Eskin and D.G. Eskin: Ultrasonic Treatment of Light Alloy Melts, 2nd ed., CRC Press, Boca Raton, 2014.

59. Z. Fan, Y. Wang, M. Xia, and S. Arumuganathar: Acta Mater., 2009, vol. 57, pp. 4891-01.

60. H. Men, B. Jiang, and Z. Fan: Acta Mater., 2010, vol. 58, pp. $6526-34$.

61. H.T. Li, M. Xia, P. Jarry, G.M. Scamans, and Z. Fan: J. Crystal Growth, 2011, vol. 314, pp. 285-92.

62. S. Kumar, N.H. Babu, G.M. Scamans, and Z. Fan: Metall. Mater. Trans. A, 2011, vol. 42, pp. 3141-49.

63. H.T. Li, Y. Wang, and Z. Fan: Acta Mater., 2012, vol. 60, pp. $1528-37$.

64. S. Das, N.S. Barekar, O. El Fakir, L. Wang, A.K.P. Rao, JB. Patel, HR. Kotadia, A. Bhagurkar, J.P. Dear, and Z. Fan: Mater. Sci. Eng. A, 2015, vol. 620, pp. 223-32.

65. N.S. Barekar, S. Das, X. Yang, Y. Huang, O. El Fakir, A.G. Bhagurkar, L. Zhou, and Z. Fan: Mater. Sci. Eng. A, 2016, vol. 650 , pp. $365-73$.

Publisher's Note Springer Nature remains neutral with regard to jurisdictional claims in published maps and institutional affiliations. 